\title{
Solvation descriptors for ferrocene, and the estimation of some physicochemical and biochemical properties
}

\author{
Michael H. Abraham, ${ }^{* a}$ Nora Benjelloun-Dakhama, ${ }^{a}$ Joelle M. R. Gola, ${ }^{a}$ William E. Acree, Jr., ${ }^{b}$ \\ William S. Cain ${ }^{c}$ and J. Enrique Cometto-Muniz ${ }^{c}$ \\ ${ }^{a}$ Department of Chemistry, University College London, 20 Gordon Street, London, \\ UKWC1H 0AJ. E-mail: m.h.abraham@ucl.ac.uk \\ ${ }^{b}$ Department of Chemistry, University of North Texas, Denton, Texas 76203-0068, USA \\ ${ }^{c}$ Chemosensory Perception Laboratory, Department of Surgery (Otolaryngology), University of \\ California, San Diego, Mail Code 0957, La Jolla, California 92093-0957, USA
}

\author{
Received (in Cambridge, UK) 26th May 2000, Accepted 14th August 2000 \\ First published as an Advance Article on the web 18th September 2000
}

\begin{abstract}
Literature data on the solubility of ferrocene in nonaqueous solvents have been combined with the aqueous solubility to give partition coefficients from water to solvents, and have also been combined with the vapour pressure at $298 \mathrm{~K}$ to give gas-solvent partition coefficients. These two sets of partitions have been analysed through the solvation equations of Abraham to yield values of the solvation descriptors. Ferrocene is shown to have about the same dipolarity/polarisability and hydrogen bond basicity as naphthalene. From the solvation descriptors, various properties of ferrocene have been estimated, including the lipophilicity, the blood-brain distribution, and the vapour toxicity (as the nasal pungency threshold).
\end{abstract}

Paramètres de solvatation du ferrocène et estimation de diverses propriétés physico-chimiques et biologiques. Les valeurs de solubilité du ferrocène dans l'eau et divers solvants organiques, tirées de la littérature, ont été utilisées afin d'obtenir les valeurs de $\log P$ exprimant le partage du ferrocène entre l'eau et chacun des solvants étudiés. De la même façon, les coefficients de partage entre phase gazeuse et phase condensée, $\log L^{\mathrm{S}}$, ont été calculés à partir de la pression de vapeur du ferrocène à $298 \mathrm{~K}$ et des valeurs de solubilité du ferrocène dans divers solvants. Ces valeurs de $\log P$ et $\log L^{\mathrm{S}}$ ont été utilisées à travers les équations de solvatation d'Abraham permettant ainsi l'obtention des paramètres de solvatation du ferrocène. Le composé ferrocène semble avoir la même dipolarité, polarisabilité et basicité de liaison hydrogène que la naphtalène. Les paramètres de solvatation ont également permis l'estimation de certaines propriétés du ferrocène telles que sa lipophilicité, sa capacité de distribution entre le sang et le cerveau et sa toxicité de vapeur comme le seuil d'irritation nasale.

A number of physicochemical properties of ferrocene at $298 \mathrm{~K}$ are known; these include the vapour pressure, ${ }^{1-7}$ the enthalpy of sublimation, ${ }^{8}$ the solubility in water, as $\log S_{\mathrm{w}}\left(-4.47,{ }^{9}\right.$ $-4.37,{ }^{10}-4.30,{ }^{11}$ and $\left.-4.17^{12}\right)$, the Henry's constant in water $\left(1.34 \times 10^{6} \mathrm{~Pa}\right)$ or the equivalent Ostwald solubility coefficient (102), ${ }^{10}$ and various electrochemical properties ${ }^{11}$ mostly relevant to the ferrocene/ferrocinium couple.

The $1: 1$ hydrogen bond basicity, $\beta_{2}^{\mathrm{H}}$, is known ${ }^{13}$ to be 0.27 , which is rather more than that for cyclohexa-1,4-diene (0.11), 14 but almost the same as that for hexamethylbenzene $\left(0.26^{13}\right.$ or $0.24^{14}$ ); the value of $\beta_{2}^{\mathrm{H}}$ for cyclopentadiene seems not to be known. A determination of the complexation of ferrocene with phenol in tetrachloromethane ${ }^{15}$ yields (cf. ref. 13) a value of 0.20 for $\beta_{2}^{\mathrm{H}}$ of ferrocene, if the observed complexation constant at $302 \mathrm{~K}$ is taken as an estimate of that at $298 \mathrm{~K}$. This value of 0.20 is in reasonable agreement with the listed value of 0.27 (see above).

However, in order to analyse solubility-related properties, it is not the $1: 1$ hydrogen bond basicity that is relevant, but the corresponding basicity when the solute is surrounded by solvent molecules, that is, ${ }^{16}$ the overall, or summation, hydrogen bond basicity. It is the aim of the present work to determine the solvation parameters for ferrocene, including the overall, or summation, hydrogen bond basicity, and to show how these parameters may be used to deduce various physicochemical properties.

\section{Methodology}

We start with the set of equations we have constructed ${ }^{16}$ for the partition of solutes between water and a given solvent, using our general solvation equation, eqn. (1), with a more simplified notation than originally given. ${ }^{16}$

$$
\log P=c+e \boldsymbol{E}+s \boldsymbol{S}+a \boldsymbol{A}+b \boldsymbol{B}+v \boldsymbol{V}
$$

In eqn. (1), the dependent variable is $\log P$, the partition coefficient of a series of solutes between water and a given solvent. The independent variables are as follows, with the original ${ }^{16}$ notation in parentheses: $\boldsymbol{E}\left(R_{2}\right)$ is the solute excess molar refractivity in units of $\left(\mathrm{cm}^{3} \mathrm{~mol}^{-1}\right) / 10, S\left(\pi_{2}^{\mathrm{H}}\right)$ is the solute dipolarity/polarisability, $\boldsymbol{A}\left(\sum \alpha_{2}^{\mathrm{H}}\right)$ and $\boldsymbol{B}\left(\sum \beta_{2}^{\mathrm{H}}\right)$ are the overall, or summation, hydrogen bond acidity and basicity, respectively and $\boldsymbol{V}(V x)$ is the McGowan characteristic volume ${ }^{17}$ with units of $\left(\mathrm{cm}^{3} \mathrm{~mol}^{-1}\right) / 100$. Table 1 gives the coefficients in eqn. (1) for the water-solvent partitions we shall consider. ${ }^{18-24}$ Note that many of these are 'hypothetical partitions' between pure water and the pure dry solvent; these are shown as 'dry' in Table 1. Although 'hypothetical', these partitions are very useful; as we show later, they can be used to predict solubilities in the pure dry solvent.

The partition coefficient of a solid between water and a solvent phase can be obtained from the solubility of the solid in water, $S_{\mathrm{w}}$, and the solvent, $S$, [eqn. (2)], provided that the 
Table 1 Coefficients in eqn. (1) for partition between water and solvents ${ }^{a}$

\begin{tabular}{|c|c|c|c|c|c|c|}
\hline Solvent & $c$ & $e$ & $s$ & $a$ & $b$ & $v$ \\
\hline n-Hexane & 0.361 & 0.579 & -1.723 & -3.599 & -4.764 & 4.344 \\
\hline n-Heptane & 0.325 & 0.670 & -2.061 & -3.317 & -4.733 & 4.543 \\
\hline n-Octane & 0.223 & 0.642 & -1.647 & -3.480 & -5.067 & 4.526 \\
\hline 2,2,4-Trimethylpentane & 0.288 & 0.382 & -1.668 & -3.639 & -5.000 & 4.561 \\
\hline Cyclohexane & 0.159 & 0.784 & -1.678 & -3.740 & -4.929 & 4.577 \\
\hline Chloroform & 0.327 & 0.157 & -0.391 & -3.191 & -3.437 & 4.191 \\
\hline Tetrachloromethane & 0.260 & 0.573 & -1.254 & -3.558 & -4.588 & 4.589 \\
\hline Benzene & 0.142 & 0.464 & -0.588 & -3.099 & -4.625 & 4.491 \\
\hline Toluene & 0.143 & 0.527 & -0.720 & -3.010 & -4.824 & 4.545 \\
\hline Carbon disulfide & 0.047 & 0.686 & -0.943 & -3.603 & -5.818 & 4.921 \\
\hline Propanone, dry & 0.335 & 0.349 & -0.231 & -0.411 & -4.793 & 3.963 \\
\hline Acetonitrile, dry & 0.413 & 0.077 & 0.326 & -1.566 & -4.391 & 3.364 \\
\hline Methanol, dry & 0.329 & 0.299 & -0.671 & 0.080 & -3.389 & 3.512 \\
\hline Ethanol, dry & 0.208 & 0.409 & -0.959 & 0.186 & -3.645 & 3.928 \\
\hline Butan-1-ol, dry & 0.153 & 0.438 & -1.177 & 0.096 & -3.919 & 4.122 \\
\hline Propan-2-ol, dry & 0.063 & 0.320 & -1.024 & 0.445 & -3.829 & 4.067 \\
\hline Ethylene glycol, dry & -0.313 & 0.419 & -0.409 & 0.906 & -2.558 & 2.771 \\
\hline Octan-1-ol, wet & 0.088 & 0.562 & -1.054 & 0.034 & -3.460 & 3.814 \\
\hline
\end{tabular}

${ }^{a}$ The solvents denoted as 'dry' are those for which partitions refer to transfer from water to the pure dry solvent. The other partitions are from water (more correctly water saturated with solvent) to the solvent saturated with water (see text).

same solid phase is in equilibrium with the saturated solutions in water and in the given solvent. ${ }^{25}$

$$
\log P=\log S-\log S_{\mathrm{W}}
$$

We can therefore use the solubility of ferrocene in water, log $S_{\mathrm{W}}=-4.47,{ }^{9}$ together with available solubilities in a variety of nonaqueous solvents, ${ }^{9,26-32}$ to deduce $\log P$ values for the partition of ferrocene from water to the solvents. These are given in Table 2. Note that if we had used the $\log S_{\mathrm{w}}$ value of $\mathrm{Wu}$ et al., ${ }^{10}$ our calculations would have been almost identical.

For partition of solutes between the gas phase and solvents, eqn. (3) is used ${ }^{16}$ instead of eqn. (1). The dependent variable is now $\log L^{\mathrm{S}}$, where $L^{\mathrm{S}}$ is the gas-solvent partition coefficient, or Ostwald solubility coefficient, for a series of solutes in a given solvent, defined as shown in eqn. (4).

Table 2 Solubilities of ferrocene, $\left(S\right.$ in $\left.\mathrm{mol} \mathrm{dm}^{-3}\right)$, and derived partition coefficients

\begin{tabular}{lllll}
\hline Solvent & $\log S$ & $\log P$ & $\log L^{\mathrm{S}}$ & Ref. (log $S)$ \\
\hline n-Hexane & -0.818 & 3.652 & 5.576 & $26,31,32$ \\
n-Heptane & -0.781 & 3.689 & 5.613 & $26-28,32$ \\
n-Octane & -0.846 & 3.624 & 5.548 & 32 \\
n-Dodecane & -0.823 & 3.646 & 5.570 & 29 \\
2,2,4-Trimethylpentane & -0.860 & 3.610 & 5.534 & 27 \\
Cyclohexane & -0.513 & 3.957 & 5.881 & $26-28,32$ \\
Chloroform & 0.372 & 4.842 & 6.766 & 31 (not used) \\
Tetrachloromethane & -0.159 & 4.311 & 6.235 & 27 \\
Benzene & -0.031 & 4.439 & 6.363 & $26,28,31,32$ \\
Toluene & -0.030 & 4.440 & 6.364 & 26,32 \\
Carbon disulfide & 0.012 & 4.482 & 6.406 & 27 \\
Propanone & -0.509 & 3.961 & 5.885 & 31 \\
Acetonitrile & -0.790 & 3.680 & 5.604 & 9 \\
Methanol & -1.050 & 3.420 & 5.344 & 9 \\
Ethanol & -1.096 & 3.374 & 5.298 & 26 \\
Butan-1-ol & -1.034 & 3.436 & 5.360 & 26 \\
Propan-2-ol & -1.048 & 3.422 & 5.346 & 31 \\
Ethylene glycol & -1.928 & 2.542 & 4.466 & 30 \\
Water & -4.47 & & 1.924 & 9 \\
Hex-1-ene & -0.303 & 4.167 & 6.091 & 32 (not used) \\
Pyridine & -0.080 & 4.390 & 6.314 & 9 (not used) \\
1,4-Dioxane & -0.116 & 4.354 & 6.278 & 27 (not used) \\
Dimethyl sulfoxide & -0.69 & 3.780 & 5.704 & 9 (not used) \\
& & & & \\
\hline & & & &
\end{tabular}

$$
\begin{gathered}
\log L^{\mathrm{S}}=c+e \boldsymbol{E}+s \boldsymbol{S}+a \boldsymbol{A}+b \boldsymbol{B}+l \boldsymbol{L} \\
L^{\mathrm{S}}=\frac{[\text { conc. of solute in solvent }]}{[\text { conc. of solute in gas phase] }}
\end{gathered}
$$

The descriptors in eqn. (3) are the same as those in eqn. (1), except that $\boldsymbol{V}$ is replaced by $\boldsymbol{L}\left(\log L^{16}\right.$ where $L^{16}$ is the gasliquid partition coefficient on hexadecane at $298 \mathrm{~K}) \cdot{ }^{33}$ Values of $\log L^{\mathrm{S}}$ for ferrocene in solvents can be obtained from the saturated vapour concentration of ferrocene at $298 \mathrm{~K}$ and the solubility in a given solvent, through eqn. (4), and are also given by eqn. (5), where $L^{\mathrm{W}}$ is the Ostwald solubility coefficient of ferrocene in water.

$$
\log L^{\mathrm{S}}=\log L^{\mathrm{W}}+\log P
$$

Ribeiro da Silva and Monte ${ }^{7}$ list eleven values of the saturated vapour pressure of ferrocene at $298 \mathrm{~K}$, ranging from 0.858 to $1.16 \mathrm{~Pa}$. We chose an intermediate value of $1.00 \mathrm{~Pa}$, corresponding to a vapour concentration $\left(C_{\mathrm{G}}\right.$ in $\left.\mathrm{dm}^{3} \mathrm{~mol}^{-1}\right)$, of $\log C_{\mathrm{G}}=-6.39$ which, combined with $\log S_{\mathrm{W}}=-4.47$, leads to a value of 1.92 for $\log L^{\mathrm{W}}$. The values of $\log L^{\mathrm{S}}$ for ferrocene in various solvents are shown in Table 2 , and the coefficients in eqn. (3) for a number of solvents are collected in Table 3.

A key descriptor is the McGowan volume that is obtained from atomic and bond contributions, ${ }^{17}$ the former from atomic parachors. ${ }^{34}$ For a number of elements, McGowan ${ }^{34}$ calculated atomic parachors for the atom in two electronic states, thus leading to two different atomic volumes. For iron, the two atomic volumes are 0.4015 and 0.0581 in our usual units of $\left(\mathrm{cm}^{3} \mathrm{~mol}^{-1}\right) / 100$. However, it seems clear from examples quoted by McGowan that transition metals have variable atomic volumes. Thus, $\mathrm{Fe}$ in $\mathrm{Fe}(\mathrm{CO})_{5}$ has $^{34}$ an atomic volume of 0.284 , intermediate between the two above volumes. We have shown previously ${ }^{24}$ that values of $\boldsymbol{V}$ are well correlated with liquid molar volumes at $298 \mathrm{~K}, V_{\text {liq }}$. For a series of cyclic compounds, the regression equation is:

$$
\begin{gathered}
\boldsymbol{V}=-0.0882+0.8837 V_{\mathrm{liq}} \\
n=20, \mathrm{sd}=0.0428, r^{2}=0.988, F=1534
\end{gathered}
$$

with both volumes in $\left(\mathrm{cm}^{3} \mathrm{~mol}^{-1}\right) / 100$. Here, $n$ is the number of data points, sd is the standard deviation, $r^{2}$ is the variance 
Table 3 Coefficients in eqn. (3) for partition between the gas phase and solvents ${ }^{a}$

\begin{tabular}{|c|c|c|c|c|c|c|}
\hline Solvent & $c$ & $e$ & $s$ & $a$ & $b$ & $l$ \\
\hline n-Hexane & 0.292 & -0.169 & 0.000 & 0.000 & 0.000 & 0.979 \\
\hline n-Heptane & 0.275 & -0.162 & 0.000 & 0.000 & 0.000 & 0.983 \\
\hline n-Octane & 0.215 & -0.049 & 0.000 & 0.000 & 0.000 & 0.967 \\
\hline 2,2,4-Trimethylpentane & 0.275 & -0.244 & 0.000 & 0.000 & 0.000 & 0.972 \\
\hline Cyclohexane & 0.163 & -0.110 & 0.000 & 0.000 & 0.000 & 1.013 \\
\hline Chloroform & 0.116 & -0.467 & 1.203 & 0.138 & 1.432 & 0.994 \\
\hline Tetrachloromethane & 0.282 & -0.303 & 0.460 & 0.000 & 0.000 & 1.047 \\
\hline Benzene & 0.107 & -0.313 & 1.053 & 0.457 & 0.169 & 1.020 \\
\hline Toluene & 0.121 & -0.222 & 0.938 & 0.467 & 0.099 & 1.012 \\
\hline Carbon disulfide & 0.101 & 0.251 & 0.177 & 0.027 & 0.095 & 1.068 \\
\hline Propanone, dry & 0.154 & -0.277 & 1.522 & 3.258 & 0.078 & 0.863 \\
\hline Acetonitrile, dry & -0.007 & -0.595 & 2.461 & 2.085 & 0.418 & 0.738 \\
\hline Methanol, dry & -0.004 & -0.215 & 1.173 & 3.701 & 1.432 & 0.769 \\
\hline Ethanol, dry & 0.012 & -0.206 & 0.789 & 3.635 & 1.311 & 0.853 \\
\hline Butan-1-ol, dry & -0.039 & -0.276 & 0.539 & 3.781 & 0.995 & 0.934 \\
\hline Propan-2-ol, dry & -0.060 & -0.335 & 0.702 & 4.017 & 1.040 & 0.893 \\
\hline Ethylene glycol, dry & -0.937 & 0.215 & 1.511 & 4.651 & 2.591 & 0.571 \\
\hline Octan-1-ol, wet & -0.198 & 0.002 & 0.709 & 3.519 & 1.429 & 0.858 \\
\hline
\end{tabular}

${ }^{a}$ The solvents denoted as 'dry' are those for which partitions refer to transfer from the gas phase to the pure dry solvent. The other partitions are from the gas phase to the solvent saturated with water (see text).

and $F$ is the $F$-statistic. There are a number of ferrocene derivatives that are liquid at $298 \mathrm{~K}$, and for which $V_{\text {liq }}$ is then available (see Table 4). From the ethyl and n-butyl derivatives we can estimate $V_{\text {liq }}$ for ferrocene itself to be 1.342 at $298 \mathrm{~K}$. Then, from eqn. (6), it is possible to estimate the corresponding values of $\boldsymbol{V}$. These can be compared with the calculated $\boldsymbol{V}$ values, using the atomic contribution of 0.0581 for $\mathrm{Fe}$. As shown in Table 4, the agreement is very good, and we can use this atomic contribution to calculate $\boldsymbol{V}$ for ferrocene to be 1.1209 in units of $\left(\mathrm{cm}^{3} \mathrm{~mol}^{-1}\right) / 100$. A value of 1.354 for $\boldsymbol{E}$ for ferrocene can be estimated from those for ethylferrocene and n-butylferrocene. It must be said, however, that the agreement between the volumes shown in Table 4 might be fortuitous. We therefore suggest that in the case of transition metals, it is much safer to assign the atomic contribution through an equation such as eqn. (6), if at all possible.

Once values of $\boldsymbol{E}$ and $\boldsymbol{V}$ are available, the remaining four descriptors in eqn. (1) and eqn. (3) can be obtained, as we have described previously. ${ }^{24,25,35,36}$ In brief, we have values of $\log$ $P$ and $\log L^{S}$ for ferrocene, derived from measured values of $\log S$, as shown in Table 2, and we have the coefficients already determined for the corresponding equations, using eqn. (1) and eqn. (3) (see Tables 1 and 3). The only unknowns are the descriptors $\boldsymbol{S}, \boldsymbol{A}, \boldsymbol{B}$ and $\boldsymbol{L}$, and these can be assigned by a least-squares procedure that minimises the observed and calculated values of $\log P$ and $\log L^{\mathrm{S}}$. We have 19 equations in $\log P$ and 19 equations in $\log L^{\mathbf{S}}$, so that our analysis covers quite a range of solvents. The $\log P$ and $\log L^{\mathrm{S}}$ values for chloroform solvent were somewhat anomalous and were omitted. The best-fit solution of the remaining 36 equations yielded the following values: $\boldsymbol{S}(0.85), \boldsymbol{A}(0.00), \boldsymbol{B}(0.20)$ and $\boldsymbol{L}$

Table 4 Liquid molar volumes, estimated McGowan volumes, through eqn. (6), and calculated McGowan volumes with $\boldsymbol{V}=0.0581$ for $\mathrm{Fe}$, all in $\left(\mathrm{cm}^{3} \mathrm{~mol}^{-1}\right) / 100$

\begin{tabular}{lllll}
\hline Compound & $V_{\text {liq }}$ & $V$ [eqn. (6)] & $V$ (calc.) & $E$ \\
\hline Dimethylaminoferrocene & 1.98 & 1.661 & 1.6434 & 1.417 \\
n-Butylferrocene & 2.066 & 1.737 & 1.6845 & 1.337 \\
Ethylferrocene & 1.704 & 1.417 & 1.4027 & 1.358 \\
Ferrocene & $1.342^{a}$ & 1.097 & 1.1209 & 1.354 \\
${ }^{a}$ Estimated from the ethyl and n-butyl derivatives. & & \\
&
\end{tabular}

(5.6244). How well these descriptors, together with $\boldsymbol{E}=1.354$ and $\boldsymbol{V}=1.1209$, reproduce the $\log P, \log L^{\mathrm{S}}$ and original $\log S$ values is shown in Table 5. The $\log S$ values can be calculated in two ways: (i) $\log S$ (calc) $=\log P($ calc $)+\log S_{\mathrm{W}}$, and (ii) $\log$ $S($ calc $)=\log L^{\mathrm{S}}$ (calc) $+\log C_{\mathrm{G}}$. Table 5 summarises the results of the calculations.

The $\log P$ values are correlated with sd $=0.098$, the $\log L^{\mathrm{S}}$ values with $\mathrm{sd}=0.101$, and the total 36 values with $\mathrm{sd}=0.098$ $\log$ units. The original $\log S$ values in the nonaqueous solvents (17 in number, if chloroform is excluded) are reproduced with sd values of 0.101 [method (i)] and 0.105 [method (ii)], average absolute deviations of 0.075 and 0.082 , and average deviations of -0.008 and 0.004 , respectively. The general method, based on eqn. (1) and eqn. (3), is therefore capable of correlating the original $\log S$ values very well, and could be used to predict further $\log S$ values in solvents for which we have the coefficients in eqn. (1) or eqn. (3), to within about 0.1 $\log$ units. This is one particular use of 'hypothetical' waterdry solvent partitions. In addition, the method provides solvation descriptors for ferrocene that can be used to compare chemical properties with those of other relevant compounds.

In Table 6 are values of the solvation descriptors in eqn. (1) and eqn. (3) for ferrocene, and for a number of other related compounds, all of which have zero hydrogen bond acidity. The $\boldsymbol{E}$ and $\boldsymbol{S}$ descriptors are in no way anomalous, and are both slightly more than those calculated for two cyclopentadienyl rings. The overall hydrogen bond basicity $(\boldsymbol{B})$, at 0.20 , is interesting in that it is only slightly smaller than that of two cyclopentadienyl rings $(2 \times 0.12)$ (see Table 6$)$ so that the $\mathrm{Fe}$ atom has only a very small effect on the availability of electron pairs for hydrogen bonding. This is also the case for the $1: 1$ hydrogen bond parameter $\beta_{2}^{\mathrm{H}}$, obtained by a completely different method. The $\boldsymbol{L}$ parameter (5.622), which is related to solute size, is substantially larger than that calculated for two cyclopentadienyl rings (4.444). This is as expected, since the $\mathrm{Fe}$ atom must contribute to any sizerelated property.

Once the solvation descriptors are available for ferrocene, it is possible to calculate a number of physicochemical and biological properties, using the general equations eqn. (1) and eqn. (3); some of these properties are collected in Table 7. Various water-solvent partition coefficients can be calculated, of which the most important is the water-octanol partition, used as an indicator of solute lipophilicity. ${ }^{37}$ The coefficients in eqn. (3) for this practical partition are given in Table 3 , and 
Table 5 Observed and calculated values of $\log S, \log P$ and $\log L^{\mathrm{s}}$ for ferrocene

\begin{tabular}{|c|c|c|c|c|c|c|c|}
\hline Solvent & $\log S$ obs. & $\log P$ obs. & $\log L^{\mathrm{S}}$ obs. & $\log S$ calc. $^{a}$ & $\log S$ calc. $^{b}$ & $\log P$ calc. & $\log L^{\mathrm{S}}$ calc. \\
\hline n-Hexane & -0.818 & 3.652 & 5.576 & -0.873 & -0.825 & 3.597 & 5.569 \\
\hline n-Heptane & -0.781 & 3.689 & 5.613 & -0.844 & -0.810 & 3.626 & 5.584 \\
\hline n-Octane & -0.846 & 3.624 & 5.548 & -0.718 & -0.807 & 3.752 & 5.587 \\
\hline n-Dodecane & -0.823 & 3.646 & 5.570 & -0.859 & -0.770 & 3.611 & 5.624 \\
\hline 2,2,4-Trimethylpentane & -0.860 & 3.610 & 5.534 & -0.970 & -0.982 & 3.500 & 5.412 \\
\hline Cyclohexane & -0.513 & 3.957 & 5.881 & -0.531 & -0.682 & 3.939 & 5.712 \\
\hline Chloroform & 0.372 & 4.842 & 6.766 & $(-0.252)$ & $(-0.011)$ & 4.218 & 6.383 \\
\hline Tetrachloromethane & -0.159 & 4.311 & 6.235 & -0.274 & -0.269 & 4.196 & 6.152 \\
\hline Benzene & -0.031 & 4.439 & 6.363 & -0.091 & -0.045 & 4.379 & 6.349 \\
\hline Toluene & -0.030 & 4.440 & 6.364 & -0.096 & -0.065 & 4.374 & 6.329 \\
\hline Carbon disulfide & 0.012 & 4.482 & 6.406 & 0.057 & 0.223 & 4.527 & 6.617 \\
\hline Propanone & -0.509 & 3.961 & 5.885 & -0.375 & -0.452 & 4.095 & 5.942 \\
\hline Acetonitrile & -0.790 & 3.680 & 5.604 & -0.783 & -0.880 & 3.687 & 5.514 \\
\hline Methanol & -1.050 & 3.420 & 5.344 & -1.048 & -1.080 & 3.422 & 5.314 \\
\hline Ethanol & -1.096 & 3.374 & 5.298 & -0.849 & -0.930 & 3.621 & 5.464 \\
\hline Butan-1-ol & -1.034 & 3.436 & 5.360 & -0.889 & -0.894 & 3.581 & 5.500 \\
\hline Propan-2-ol & -1.048 & 3.422 & 5.346 & -1.050 & -1.080 & 3.420 & 5.314 \\
\hline Ethylene glycol & -1.928 & 2.542 & 4.466 & -1.969 & -2.026 & 2.501 & 4.368 \\
\hline Water & -4.470 & & 1.924 & & & & 1.938 \\
\hline Water & -4.470 & & 1.924 & & & 1.948 & \\
\hline Hex-1-ene & -0.303 & 4.167 & 6.091 & & & $\mathrm{~N} / \mathrm{A}$ & \\
\hline Pyridine & -0.080 & 4.390 & 6.314 & & & $\mathrm{~N} / \mathrm{A}$ & \\
\hline 1,4-Dioxane & -0.116 & 4.354 & 6.278 & & & $\mathrm{~N} / \mathrm{A}$ & \\
\hline Dimethyl sulfoxide & -0.690 & 3.780 & 5.704 & & & $\mathrm{~N} / \mathrm{A}$ & \\
\hline
\end{tabular}

Table 6 Comparisons of some properties of ferrocene

\begin{tabular}{|c|c|c|c|c|c|c|c|}
\hline Compound $^{a}$ & $E$ & $S$ & $B$ & $V$ & $L$ & $\beta_{2}^{\mathrm{H} b}$ & $\log P_{\text {oct }}$ \\
\hline Ferrocene & 1.35 & 0.85 & 0.20 & 1.121 & 5.622 & $0.20 / 0.27$ & $3.54^{c}$ \\
\hline Benzene & 0.61 & 0.52 & 0.14 & 0.716 & 2.786 & $0.15 / 0.15$ & 2.13 \\
\hline Biphenyl & 1.36 & 0.99 & 0.26 & 1.324 & 6.014 & $0.20 / 0.20$ & 4.01 \\
\hline Naphthalene & 1.34 & 0.92 & 0.20 & 1.085 & 5.161 & $0.21 / 0.21$ & 3.30 \\
\hline Cyclopentadiene & 0.42 & 0.35 & 0.12 & 0.618 & 2.222 & & $1.89^{d}$ \\
\hline 1,3-Cyclooctadiene & 0.60 & 0.35 & 0.14 & 1.041 & & $0.13 / 0.13$ & \\
\hline Butanone & 0.17 & 0.7 & 0.51 & 0.688 & 2.287 & 0.48 & 0.29 \\
\hline Dimethylformamide & 0.37 & 1.31 & 0.74 & 0.647 & 3.173 & 0.66 & -1.01 \\
\hline
\end{tabular}

${ }^{a}$ All listed compounds have a zero value for $\boldsymbol{A} .{ }^{b}$ Ref. 13 and $15 .^{c}$ Observed values are 2.66 (ref. 38) and 3.46 (ref. 39), see text. ${ }^{d}$ Calculated $C$ log $P$ value, ref. 38

lead to a predicted value of 3.54 for $\log P_{\text {oct }}$. However, the most recent issue of the MedChem data base ${ }^{38}$ lists an unpublished measured value of 2.66 for $\log P_{\text {oct }}$, which would imply that our calculations are in error. We were fortunate that Dr Bryan Slater offered to re-measure $\log P_{\text {oct }}$; the new measured value is $3.46 \pm 0.03$ as an average of three separate determinations. ${ }^{39}$ Our predicted value of 3.54 is in excellent agreement with the measured value, and so we have some confidence in our ability to predict properties of ferrocene.

Some comparisons of lipophilicity are in Table 6; ferrocene is rather strongly lipophilic, of the same order as aromatic compounds with two rings, such as biphenyl and naphthalene.

Table 7 The predictions for some properties of ferrocene

\begin{tabular}{llr}
\hline Property & Details & Value \\
\hline Lipophilicity & $\log P_{\text {oct }}$ & 3.54 \\
$\Delta \log P_{\text {cyc }}$ & $\Delta \log P$ & -0.45 \\
Blood-brain distribution & $\log B B$ & 0.64 \\
Skin permeation & $\log \mathrm{kp} / \mathrm{cm} \mathrm{s}^{-1}$ & -3.40 \\
Nasal pungency threshold & $\mathrm{NPT} / \mathrm{ppm}$ & 37
\end{tabular}

Another well-known descriptor that is often used in quantitative structure-activity relationships is the $\Delta \log P$ parameter of Seiler, ${ }^{40}$ defined as:

$$
\Delta \log P=\log P_{\text {oct }}-\log P_{\text {cyc }}
$$

where $P_{\text {cyc }}$ is the water-cyclohexane partition coefficient. Our calculated negative value $(-0.45)$ for $\Delta \log P$ is as expected $^{18,41}$ for a solute with zero hydrogen bond acidity. The blood-brain distribution of ferrocene can be estimated ${ }^{42}$ to be 0.64 , putting it near the middle of the observed range $(-2.2$ to +1.4$) .^{43}$ On the other hand, our calculated value for permeation from water through human skin, ${ }^{44} \log k p=-3.4$ with $k p$ in units of $\mathrm{cm} \mathrm{s}^{-1}$, would make ferrocene one of the most penetrative compounds known. ${ }^{44}$ Properties of gaseous ferrocene can be estimated through eqn. (3); for example, the nasal pungency threshold, an indicator of the toxicity of vapours, can be estimated through our previously published equation $^{45}$ as $37 \mathrm{ppm}$. In comparison to a very poorly potent vapour, methyl acetate, with a measured threshold of $1.1 \times 10^{5} \mathrm{ppm}$ and a very potent vapour, dodecyl acetate, with a measured threshold of $1.3 \mathrm{ppm}$, ferrocene is potentially quite potent. However, the very low vapour pressure of ferrocene $(1.00 \mathrm{~Pa}$ at $298 \mathrm{~K})$ corresponds to a vapour concentra- 
tion of only $9.9 \mathrm{ppm}$, so that the threshold concentration will not be reached.

\section{Acknowledgements}

We thank the EU Socrates exchange programme for allowing Nora Benjelloun Dakhama, from the CPE Lyon, to study at University College London, and we are grateful to the Center for Indoor Air Research for support of this work. We thank Dr Bryan Slater for kindly measuring the water-octanol partition coefficient of ferrocene.

\section{References}

1 J. W. Edwards and G. L. Kingston, Trans. Faraday Soc., 1962, 58, 1323

2 J. T. S. Andrews and E. F. Westrum, Jr., J. Organomet. Chem., 1969, 17, 349.

3 J. C. G. Calado, A. R. Dias, M. E. Minas da Piedade and J. A. Martinho Simoes, Rev. Port. Quim., 1980, 22, 53.

4 M. Pelino, M. Tomassetti, V. Piacente and G. D'Ascenso, Thermochim. Acta, 1981, 44, 89.

5 M. H. G. Jacobs, P. J. Van Ekeren and C. G. de Kruif, J. Chem. Thermodynam., 1983, 15, 619 .

6 L. A. Torres-Gomez, G. Barreiro-Rodriguez and F. MendezRuiz, Thermochim. Acta, 1988, 124, 179 .

7 M. A. V. Ribeiro da Silva and M. J. S. Monte, Thermochim. Acta, 1990, 171, 169

8 See ref. 7 for a comprehensive list of experimental values.

9 (a) J.-L. Brisset, J. Chem. Eng. Data, 1982, 27, 153; (b) J.-L. Brisset, J. Chem. Eng. Data, 1985, 30, 381.

10 J.-S. Wu, K. Toda, A. Tanaka and I. Sanemasa, Bull. Chem. Soc. Jpn., 1998, 71, 1615.

11 J. Georges and S. Desmettre, Electrochim. Acta, 1984, 29, 521

12 P. V. Fabinskii, E. A. Dem'yanenko, A. V. Sachivko, V. P. Tverdokhlebov and V. A. Fedorov, Russ. J. Phys. Chem., 1998, 43, 1288

13 M. H. Abraham, P. L. Grellier, D. V. Prior, J. J. Morris and P. J. Taylor, J. Chem. Soc., Perkin Trans. 2, 1990, 521.

14 F. Besseau, C. Laurence and M. Berthelot, Bull. Soc. Chim. Fr., 1996, 133, 381.

15 Z-I. Yoshida and E. Osawa, J. Am. Chem. Soc., 1966, 88, 4019.

16 M. H. Abraham, Chem. Soc. Rev., 1993, 22, 73.

17 M. H. Abraham and J. C. McGowan, Chromatographia, 1987, 23, 243.

18 M. H. Abraham, H. S. Chadha, G. S. Whiting and R. C. Mitchell, J. Pharm. Sci., 1994, 83, 1085.
19 M. H. Abraham, J. A. Platts, A. Hersey, A. Leo and R. W. Taft, J. Pharm. Sci., 1999, 88, 670.

20 M. H. Abraham, G. S. Whiting, P. W. Carr and H. Ouyang, $J$. Chem. Soc., Perkin Trans. 2, 1998, 1385.

21 M. H. Abraham, G. S. Whiting, W. J. Shuely and R. M. Doherty, Can. J. Chem., 1998, 76, 703 .

22 M. H. Abraham, J. Le, W. E. Acree, Jr. and P. W. Carr, J. Phys. Org. Chem., 1999, 12, 675 .

23 M. H. Abraham, J. Le and W. E. Acree, Jr., Collect. Czech. Chem. Commun., 1999, 64, 1748.

24 M. H. Abraham, C. G. Green and W. E. Acree, Jr., J. Chem. Soc., Perkin Trans. 2, 2000, 281

25 M. H. Abraham, C. E. Green, W. E. Acree, Jr., C. E. Hernandez and L. E. Roy, J. Chem. Soc., Perkin Trans. 2, 1998, 2677.

26 V. A. Isaenko, S. P. Gubio and M. Y. Nikulin, Izv. Sib. Otd. Acad. Nauk SSSR, 1974, 80

27 O. Jons and J. Chr. Gjaldbaek, Acta Chem. Scand. Ser. A, 1974, 28, 528 .

28 A. A. Pendin, P. K. Leont'evskaya and E. F. Korobchenko, Russ. J. Phys. Chem., 1979, 53, 1271

29 J. Georges and A. Berthod, J. Electroanal. Chem., 1984, 175, 143.

30 A. A. Pendin, S. O. Karabaev and O. M. Susareva, Russ. J. Phys. Chem., 1987, 61, 502 .

31 A. A. Pendin, L. G. Vasil'eva, S. O. Karabaev and O. M. Susareva, Russ. J. Phys. Chem., 1990, 64, 935.

32 V. D. Matveev and I. V. Stasenko, Russ. J. Gen. Chem., 1994, 64, 725 .

33 M. H. Abraham, P. L. Grellier and R. A. McGill, J. Chem. Soc., Perkin Trans. 2, 1987, 797.

34 J. C. McGowan, Rec. Trav. Chim. Pays-bas, 1956, 75, 193

35 M. H. Abraham, R. Kumarsingh, J. E. Cometto-Muniz, W. S. Cain, M. Roses, E. Bosch and M. L. Diaz, J. Chem. Soc., Perkin Trans. 2, 1998, 2405

36 C. E. Green, M. H. Abraham, W. E. Acree, Jr., K. M. De Fina and T. L. Sharp, Pestic. Sci., in press.

37 P. Buchwald and N. Bodor, Curr. Med. Chem., 1998, 5, 353.

38 A. J. Leo, MedChem 2000, The Medicinal Chemistry Project, Pomona College, Claremont, CA 91711

39 B. Slater, personal communication.

40 P. Seiler, Eur. J. Med. Chem., 1974, 9, 473

41 N. El Tayar, R.-S. Tsai, B. Testa, P.-A. Carrupt and A. J. Leo, J. Pharm. Sci., 1991, 80, 590.

42 M. H. Abraham, H. S. Chadha and R. C. Mitchell, J. Pharm. Sci., 1994, 83, 1257.

43 J. M. Luco, J. Chem. Inf. Comp. Sci., 1999, 39, 396.

44 M. H. Abraham, F. Martins and R. C. Mitchell, J. Pharm. Pharmacol., 1997, 49, 858.

45 M. H. Abraham, R. Kumarsingh, J. E. Cometto-Muniz and W. S. Cain, Arch. Toxicol., 1998, 72, 227. 